\title{
Community Service and Experiential Language Learning
}

\section{David J. Beck and Catherine Simpson}

Recent developments in experiential language learning have indicated a tremendous potential to go beyond the traditional classroom agenda. The following paper outlines some of the benefits of experiential learning and describes an experiential volunteer-work program along with a case study illustrating the wide range of opportunities for linguistic and personal growth offered by this type of program. Finally a discussion of some possible avenues for future development is offered.

The last few years have seen a dramatic increase in the number of foreign students in Canada, and particularly in B.C., enrolled in English language training courses whose primary function is the improvement of overall language skills rather than preparation or support for a specific post-secondary program or institution. Many of these students come to Canada for the advantages of immersion and of access to the community, culture, and linguistic resources that go with living in an English-speaking country - resources that are not only of benefit to the language-learner, but which can also be capitalized on by the language-educator. In an effort to do just this, the Victoria Language Institute has undertaken the development of a Community Service program to get students out into the community by placing them in volunteer situations that provide both motivation and context for the acquisition of authentic language and socio-linguistic skills through experiential learning.

\section{EXPERIENTIAL LEARNING}

Eyring (1991) characterizes experiential learning as learning that takes place in activities that integrate skills, involve both right- and left-brain functions, contextualize content, and provide real purposes for the learner; in addition, experiential language learning "deliberately teaches learners, as whole people, about how to learn" (p. 347). Eyring then goes on to develop a two-axis categorization of experiential learning activities which places activities in one of four quadrants formed by the intersection of a vertical "control" axis (which ranges from teacher-controlled to student-controlled) and a horizontal "location" axis (ranging from classroom-centred to realworld-centred). In the teacher-controlled/classroom-centred quadrant fall those activities which involve the use of props, media, 
visuals, realia, songs, and language games, while in the student-controlled/classroom-centred quadrant are classified role-plays, simulations, hands-on projects, and certain types of C.A.L.L. activities. The teacher-controlled/real-world activities would include field trips and "observation/collection" such as scavenger hunts. The final quadrant in the scheme, student-controlled/real-world, is the one highlighted by Eyring (1991, p. 349) as having the greatest potential in achieving the goals of experiential language learning. On the smallest scale, student-controlled/real-world activities can encompass activities such as those enumerated by Jerald and Clark (1989), which include exercises such as telephoning, interviewing, and participation in volunteer fund-raisers, while on the largest scale they can take the form of English in the Work Place programs (see for example Laird, 1977; Mohan, 1986; Nunan, 1988), the work study programs cited by Eyring herself (1991), and volunteer programs such as Community Service.

Another example of this type is the project described by Carter and Thomas (1990), in which learners prepared over a period of several weeks to teach public school classes of eight to eleven year old children, resulting in the development of "an unexpected facility with and awareness of language use, in a context that allowed [students] to develop as individuals" (p. 224). Gains in language ability and strategic competence were complemented by a deepening cultural awareness, making the students in the program confident, genuine users of the language. Fried-Booth (1986) enumerates a number of other advantages of experiential language learning such as increased student motivation, the integration of the four language skills in experiential tasks, and their usefulness in carrying over language learned in the classroom to active use in the outside world, while Eyring (1991) cites research to the effect that

Providing real or quasi-real life experiences allows more opportunities for language learners to receive input. Interacting and cooperating with others allows opportunities for feedback on one's own language learning and humanizes the learning process. (p. 347)

Thus the potential benefits of experiential language learning are tremendous, and it was with these in mind that it was decided to include Community Service as a component of the V.L.I. curriculum. 


\section{COMMUNITY SERVICE}

The initial concept of Community Service was a simple one: one day a week students were to be sent out individually as volunteers to selected community organizations to perform the same kinds of tasks as Canadian volunteers, and the curriculum consisted of a set of general goals for the overall program, including objectives centred on socio-linguistics and the learning of culture. This straightforward approach, however, ran into some immediate problems. The first student to go through the program was a young Japanese woman, mid- to high-beginner, who was placed in a retirement home. After her first visits, she reported feeling discouraged and under-utilized, and we found that she was often left to herself or ended up performing menial tasks that required little interaction with the residents. Although some informal arrangements had been made with the retirement home, they seemed a little uncertain as to what to do with this foreign studentparticularly as she spoke so little English-and it proved difficult for them to find the time for the supervision and planning required to ensure maximum benefit both to the institution and to the student's language learning.

As a result of this lacklustre beginning, it was decided that a more rigorous approach was called for, including better preparation of students and volunteer organizations as well as some changes in the administration of the program itself. The first administrative move was the re-definition of the position of Community Service Coordinator, which had been limited to contacting volunteer organizations and had encompassed other activities for students within the larger V.L.I. program. Responsibility for these activities was passed on to other staff members and Community Service became the coordinator's primary focus-beginning with the development, with senior staff, of a curriculum for each type of placement (see Appendix A) on the basis of which she was to negotiate clear job descriptions with the volunteer organizations, and choice of placement with students based on preference and English level. Monitoring procedures such as regular phone contacts with organizers and on-site evaluations of the placement's utility (for both student and the organization) were also assigned to the coordinator, as were student orientation and the arrangement of a volunteer fair.

Because many of our students are Japanese, for whom the concept of volunteerism is an unfamiliar one that carries with it the notion of "working for free", student orientation was made a priority and, instead of throwing students into volunteer work unprepared, it 
was decided to ease them into their placements, beginning with group tours of a variety of community organizations. The object of these visits was not only to reduce the anxiety of stepping into a complete unknown, but also to give them an idea of what kind of things might be expected of them and, in many cases, to convince them of their ability to function in a placement at all. The week after these visits was the Volunteer Fair. At the fair, participating organizations were asked to give short, twenty-minute workshops outlining the aims and goals of their group, a description of the various programs they offer that use volunteers, and a job description for the volunteer placement(s) they had; many organizations made use of audio-visual aids such as picture displays or slides, and all were asked to reserve five or ten minutes at the end of each presentation to answer questions. This question period was seen as particularly important because, in addition to providing students with face-to-face contact with potential co-workers, it gave the volunteer representatives a chance to get an idea of the students' language ability and provided a forum for interaction, in some cases for the first time, with a foreign learner of English. Armed with this experience, the organizations themselves were able to set realistic goals and adjust their expectations of student volunteers, which was especially useful in the planning of the on-site orientation for newly placed students. The on-site orientation, carried out by the organization's volunteer supervisor with the assistance of a part-time V.L.I. staff member, included a tour of the facilities, introduction to colleagues, work hours and duties, and practicalities such as transit routes and schedules. After orientation, students were usually left at the job site to observe the workings of the organization and ease their way into the placement. Results this time were much better and final evaluations revealed not only high student satisfaction but also that students had benefitted from their experience in a variety of ways that had been in no way foreseen in the planning stages.

\section{NAOMI: A CASE STUDY}

A particularly interesting case in point is that of Naomi, a twentysix year old student at the beginner level in oral proficiency but who had scored significantly above that level in reading and writing skills. Teachers attributed this disparity to her education in Japan (a college degree in English Literature) and to her being painfully shy and hesitant when speaking both in and out of class. The volunteer placement that Naomi chose was at Goldstream Provincial Park, about twenty minutes northwest of Victoria, helping research 
and translate tourist materials for Japanese visitors. This placement was unusual in and of itself in that Community Service had been originally conceived of as a forum for primarily oral learning and interaction; nevertheless, given Naomi's interest in the job and her predisposition for writing and translation, the placement was approved and she was sent to the park. As expected, she initially found the task enormously difficult: the level of the material she was working with was high and involved a good deal of technical language dealing with the spawning of fish and the biology of the park. After the first week of her placement, she reported that it had taken her five hours to translate the one-hundred fifty word opening paragraph of one of the brochures. Nevertheless, her motivation for the task was high enough that she persevered. She spent a great deal of time outside of class in the company of teachers and other staff working on her translations and doing other written assignments, and often issues that had arisen during her Community Service work came up in class. By the seventh week of the placement, Naomi's translation speed had improved immensely. She had moved on to original material compiled from diverse written sources and gathered orally from park naturalists, prepared in English, and then translated into Japanese, and her command of written English had improved to the point of occasionally correcting the oversights of the teacher who was helping to edit her work.

While much of this dramatic improvement can be attributed to Naomi's exposure to genuine input from informants in an authentic setting-the anticipated benefits of volunteer placements-a number of other psychological factors came into play as well. The first of these was Naomi's feeling of acceptance into the linguistic community. From day one of the placement, she was treated as a member of the park staff; she was given a desk and an office-shared, to her delight, with a handsome young bachelor-and made to feel completely at home and on an equal footing with the staff. As a result, she had the sense that both she and her work were taken seriously and that others (non-teachers) had confidence in her English ability as well as in her ability to perform a useful and difficult task, which went a long way to raising her own level of motivation and self-confidence. This acceptance, of course, also placed a good deal of pressure on her to succeed, and-given Naomi's rather nervous disposition-the first few weeks of the placement were mixed with a good deal of apprehension. Her fear was even further compounded when, in the seventh week, Naomi was asked to address a group of short-term V.L.I. students at the park in English and to lead them on a gold-panning expedition. 
This was an optional assignment and in the week or so leading up to it she was visibly nervous and at times seemed so close to terrified that some of the teaching staff expressed concern. When asked if she wanted to withdraw, however, she refused and on the big day gave an outstanding presentation. Leaving Goldstream Park, Naomi took away with her not only the appreciation of her co-workers (along with a beautiful volunteer certificate) and the knowledge that the work she had done would be published and distributed to Japanese tourists, but the grand accomplishment of having overcome her shyness and fear of functioning in a second language.

\section{DISCUSSION}

While Naomi's success might be more spectacular than most, her case is typical in the way her learning experience branched out into so many different and unexpected areas of personal and psychological growth, areas that have long been recognized as important factors in language learning (Krashen, 1983; Dubin \& Olshtain, 1986) but which have been problematic in terms of their inclusion in the classroom. The recent introduction of a student evaluation form sent out to student placements (see Appendix B) has also shown that students in the Community Service program, as did participants in the Carter and Thomas study (1990), became more confident and active users of the language in a wide variety of settings and for a wide range of purposes. Our observation has also been that many students, like Naomi, become active planners of many aspects of their language learning, bringing to the classroom their own agendas and a new-found awareness of their own needs and of the need to become owners of the language-learning process.

Another promising feature of Community Service is its capacity to teach interaction in the second language-not just how to use language to communicate meaning, but how to use the language to interact with people on a personal and professional basis. In order to facilitate this it will be necessary to analyze the interaction of the student with the people around them in their Community Service placement and collect data from both students and co-workers as to the successes and difficulties encountered. Using this information, combined with a thorough language situation analysis such as that described by Mohan (1986) and the evaluations of student performance by placement supervisors, preparations are being made for the implementation of prep classes especially dedicated to specific types of placement which address the linguistic and sociolinguistic concerns of all those students who have been placed, for 
example, in daycares or in retirement homes. At present steps are being taken to include topics from Community Service in the regular classroom as well, but it is still unclear in what way it is possible to move beyond the immediate problems of language and into the realms of unstructured interaction or affective psychology, and a great deal of work needs to be done before we have explored all the possibilities of this exciting area of language teaching.

\section{NOTE}

The authors are very interested in hearing from other people who are involved in this kind of program or who have ideas or suggestions about some of the possibilities offered by the Community Service program.

\section{THE AUTHORS}

David Beck is the curriculum and program designer for the Victoria Language Institute in Victoria, B.C., where he is currently involved in the development of content-based and experiential programs; he has taught E.S.L. previously in Canada and Nicaragua.

Catherine Simpson is the former Community Service Coordinator for the Victoria Language Institute where she also taught E.S.L. and did research and curriculum design for community-oriented programs, working with individual students to maximize their community involvement. She has taught E.S.L. for the past six years in Japan and Canada.

\section{REFERENCES}

Carter, G. \& Thomas, H. (1990). Dear brown eyes: Experiential learning in a project-orientated approach. In R. Rossner \& R. Bolitho (Eds.), Currents of change in English language teaching (pp. 215-225). East Kilbride, Scotland: Oxford University Press.

Dubin, F. \& Olshtain, E. (1986). Course design: Developing programs and materials for language leaming. New York: Cambridge University Press.

Eyring, J. (1991). Experiential language learning. In M. Celce-Murcia (Ed.), Teaching English as a second or foreign language, 2nd. edition (pp. 346-357). Boston: Heinle \& Heinle.

Fried-Booth. D. (1986). Project work. Oxford: Oxford University Press.

Jerald, M. \& Clark, R. C. (1989). Experiential language teaching techniques. U.S.A.: Pro Lingua Associates.

Krashen, S. (1982). Principles and practice in second language acquisition. Oxford: Pergamon.

Krashen, S. \& Terrell, T. (1983). The natural approach: Language acquisition in the classroom. Oxford: Pergamon.

Laird, E. (1977). Introduction to functional language training in the work place. Southall, Middlesex: National Centre for Industrial Language Training. 
Mohan, B. (1986). Language and content. Reading, Massachusetts: AddisonWesley.

Nunan, D. (1988). The Leamer-centred curiculum. London: Cambridge University Press.

Richards, J. \& Rodgers, T. (1986). Approaches and methods in language teaching. New York: Cambridge University Press.

\section{APPENDIX A}

A sample of goals and objectives for Community Service placements is given below:

\section{Daycare and Pre-School Programs}

Daycare centres and pre-schools are ideal places to arrange Comnunity Service placements in that they present optimal conditions for language exposure and acquisition. In most pre-schools and in the larger group daycares there is a ratio of about twenty children and two adults per student; children are spontaneous and expressive, speak out treely, and ask many questions; they are also non-threatening and do not represent the same kind of risk for a non-native speaker as do adults, which helps lower the affective barrier. In addition, the language used by children is often simpler than that used by adults and is thus ideal for lower-level students, and we have observed children often refusing to accept incorrect language as input even if it is semi-comprehensible, which forces students to produce grammatically correct, competent sentences.

Program-specific goals:

a) to provide opportunities for constant listening and regular checking for comprehension.

b) to expose students to the most recent Western methods of childcare and child-rearing and allow them to compare Western philosophies of teaching children with those of Japan.

c) to give students on-going "lessons" in Canadian culture by observing children at play and learning about the children's role models.

d) to help students learn colloquial speech, common expression, and nonverbal communication by watching the children at play.

e) to allow students to learn about the relationship between Canadian early childhood educators and the children they instruct.

f) to teach students to follow planned instructions and carry out activities with individual children and in groups.

g) to teach students to understand the importance of children's art and to extract meaning from it.

h) to give students the opportunity to talk to educators about their experience with the children and get feedback on it.

\section{Objectives:}

a) to have students do research to find out which stories and books are suitable for a particular age or gender group of children.

b) to have students read children's stories in English, ask the children questions, give prompts and help them word their answers correctly.

c) to practise English by explaining vocabulary verbally and nonverbally.

d) to have students spend time learning English songs with the children. 
e) to have students learn how to construct music makers and play music with the children.

f) to have students discuss plans for outings which are educational for the children and have students design questions or projects related to the outing to reinforce the children's learning experience.

g) to have students accompany the children on the outings and help supervise the children.

h) to have students participate in performing puppet plays based on English stories and fables using voices that portray different characters.

i) to have students help leaders prepare snacks for children and eat with them.

j) to have students teach the children about Japanese culture and Japanese food and have the children teach students about Canadian food and culture.

k) to have the students help organize the children for outdoor sports and games and teach the children how to play Japanese games.

1) to arrange outside activities that involve the students and the children in learning about live animals and how to protect the environment.

$m$ ) to have students learn the significance of children's art and the philosophy of analyzing it.

n) to have students watch and take part in many creative and artistic activities with the children.

o) to have students discuss the children's art with them and with the educators.

\section{APPENDIX B}

The following is an evaluation form sent out at the end of each semester to community organizations involved in our program.

\section{Community Services Evaluation}

1) Did the student display a genuine interest and involvement in their volunteer placement? Yes No

2) Did you find the student to be needed and useful within your organization?

$$
\text { Yes No }
$$

3) Was there an opportunity for the student to lead a group in a cultural demonstration or craft? Yes No

If yes, what was the response to the demonstration?

Poor Fair Good Very Good Excellent

4) How much English do you feel the student spoke and heard?

None A little Some A for

5) Did the student have a chance for any one to one conversation?

$$
\text { Yes No }
$$


6) Did the other staff members accept the student and interact well with them? Yes No

7) How well do you feel the student participated and interacted within a group setting?

Poor Fair Good Very Good Excellent

8) How well did the student accept responsibility?

Poor Fair Good Very Good Excellent

9) During the weeks that the student has been working with you have you noticed any changes in their communicative skills?

Examples of such changes may be

(please tick if appropriate)

- more willing to get into conversation

- more able to read and fill out forms

- more able to follow instructions, etc. or let you know when they can't understand

- clearer pronunciation

- expanded vocabulary

- more appropriate ways of speaking in a variety of circumstances

- more confident ways of speaking

Can you give any examples of the above?

Thank you for your assistance. 